\title{
Studies of Sedimentation Rates of Non-Transition Alkaline- Earth Metal Carbonates in Aqueous Medium
}

\author{
C. C. Obunwo ${ }^{1 *}$, A. A. Abia $^{2}$, S. D. Iboroma ${ }^{1}$ \\ ${ }^{I}$ Department of Chemistry, Rivers State University of Science \& Technology, Port Harcourt, Nigeria. \\ ${ }^{2}$ Department of Chemistry, University of Port Harcourt, Choba, Port Harcourt, Nigeria.
}

\begin{abstract}
Rate data of sedimentation are useful in designing sedimentation equipment and in modeling operations such as filtration, fluidization, two-phase flow operations, and in environmental engineering. This study was thus embarked on to obtain empirical data on the gravitational sedimentation rates of magnesium and calcium carbonates (non-transition alkaline-earth metal carbonates) by determiningthe effect of reactant concentration and size of settling vessel of these carbonates, in chemical precipitation, by a modified approach of the 'isolation method'.The results showed that the sedimentation behaviour varied with the ionic concentrations of the chemical species involved in precipitation. Initial settling characteristics also showed that the nature of the precipitates and the medium in which the precipitation occurred affected the sedimentation rates of the metal carbonates. When the metal ion concentration was varied,-0.87 and -1.1 were obtained as sedimentation orders and $9.92 \times 10^{-4} \mathrm{~cm} \mathrm{~s}^{-1} M^{-1}$ and $6.82 \times 10^{-4} \mathrm{~cm} \mathrm{~s}^{-1} M^{-1}$ as sedimentation rate constants for magnesium carbonate and calcium carbonate respectively. On the other hand,when the carbonate ion concentration was varied, -0.79 and -1.8 were obtained as sedimentation orders and $9.87 \times 10^{-4} \mathrm{~cm} \mathrm{~s}^{-1} \mathrm{M}^{-1}$ and $6.92 \times 10^{-5} \mathrm{~cm} \mathrm{~s}^{-1} M^{-1}$ as sedimentation rate constants for magnesium carbonate and calcium carbonate respectively.Sedimentation rate constants of $\mathrm{MgCO}_{3}$ and $\mathrm{CaCO}_{3}$ also showed close dependence on their densities $\left(r^{2}=0.9963\right)$. The results of the sedimentation rates measured in cylinders of varying sizes showed that the sedimentation rate of the precipitates correlated positively with the internal diameter of the cylinders.
\end{abstract}

Keywords: Sedimentation, Sedimentation rate, Sedimentation order, Sedimentation rate constant, $\mathrm{MgCO}_{3}$, $\mathrm{CaCO}_{3}$, cylinder size.

\section{Introduction}

Sedimentation is the settling out of solid particles (sediments) in a liquid by gravity (Atkins \& Paula, 2006). A fundamental dynamic property of this phenomenon is its rate which depends on density, size and shape of the particles. The phenomenon has been employed in the determination of molecular weights of proteins and applied in many engineering operations.

Sedimentation rate data play important roles in the design of sedimentation equipment as well as in the modeling of two-phase flow operations (Senthilkumar, et. al., 2008). Sedimentation studies also form an important aspect of geological research in sediments and sedimentary rocks. Stoke's law shows that the rate of sedimentation of a particle depends on the size of the particle, density of the particle, density of the medium, viscosity of the medium, and acceleration due to gravity. However,experiments on batch settling tests show that various factors including particle size distribution, shape, density andthe type of containing vesselaffect settling characteristics of particulate suspension (Nilufer, 2006).

Precipitation, on the other hand, is the process that produces a separable solid phase within a liquid medium. These solid phase particles can settle to the bottom under gravity, as sediments, if left to stand.This phenomenon can be monitored to determine sedimentation rates, sedimentation constants and sedimentation orders of the insoluble compounds. These parameters have been determined for some insoluble transition metal hydroxides (Essien, 1992), cobalt(II) insoluble compounds (Essienand Ekpe, 1998) and insoluble transition metal carbonates (Mkpenie and Onwu, 2006).

There is, however, dearth of empirical sedimentation data on non- transition alkaline - earth metal (magnesium and calcium) carbonates in aqueous medium; hence this study by employing a modified approach of the 'isolation method'.

\section{Materials And Methods}

All chemicals used were of analytical grade. Theseincluded: $\mathrm{Mg}\left(\mathrm{NO}_{3}\right)_{2} \cdot 6 \mathrm{H}_{2} \mathrm{O}, \mathrm{Ca}\left(\mathrm{NO}_{3}\right)_{2} \cdot 4 \mathrm{H}_{2} \mathrm{O}$ and $\mathrm{Na}_{2} \mathrm{CO}_{3}$ (anhydrous). Digital stopwatch, thermometer, vernier calipers, measuring cylinders $(25 \mathrm{ml}, 50 \mathrm{ml}$, 
$100 \mathrm{ml}, 250 \mathrm{ml}, 500 \mathrm{ml})$, volumetric flasks $(250 \mathrm{ml}$ and $1000 \mathrm{ml})$, and stirrers were also used. All preparations were carried out using distilled water and salts weighed using a scout pro digital balance.

Determination of Sedimentation Rates:A modified approach ofthe method of initial rates (Atkins \& Paula, 2006), also known as 'isolation method' (Raymond, 1981), was used for this study. The approach involved measurement of initial rates of sedimentation of precipitates formed, at the beginning of the settling process.

Standard aqueous solutions of magnesium nitrate (or calcium nitrate) and sodium carbonate of concentrations ranging between $0.01 \mathrm{M}$ and $0.11 \mathrm{M}$ were separately prepared.A precipitate was formed by the mixture of $40 \mathrm{mls}$ of each of the solutions in a $100 \mathrm{ml}$ cylinder.The cylinder was bench-mounted and provided with back lighting (100-watts white fluorescent bulb) to enhance illumination and accurate monitoring (Armfield, 2011).The time for every one centimeter change in height of the precipitates-supernatant interface was monitored and recordedimmediately after stirring. Sedimentation of the precipitates was monitored by varying the initial concentrations of the metal ion ( $\mathrm{Mg}$ or $\mathrm{Ca}$ ) while keeping the carbonate ion (the precipitating agent) concentrations constant at $0.05 \mathrm{M}$. Similarly,sedimentation of the precipitates was monitored by varying the initial concentrations of the carbonate ions while keeping the metal ion concentration constant at $0.05 \mathrm{M}$.

Sedimentation rate (Rs) was calculated from the slope (at the initial settling stage) of the plot of change in height $(\mathrm{CH})$ against settling time $(\mathrm{t})$. The sedimentation order and sedimentation rate constant were obtained by plotting a graph of log-sedimentation rate versus log-concentration and taking a best-fit regression line through the known $\mathrm{x}$ - and $\mathrm{y}$-values.

Sedimentation of precipitates (magnesium or calcium carbonate) was also monitored in measuring cylinders of various sizes $(25 \mathrm{ml}-500 \mathrm{ml})$. 0.01 Msolution of metal nitrate was reacted with $0.05 \mathrm{M}$ solution of sodium carbonate to generate the precipitate. These concentrations were carefully chosen to minimize particles super-saturation in the resulting mixture and to promote the formation of small number of precipitates, with appreciable particle size, which could settle with minimal inter-particle hindrance. After mixing to form the precipitate, the resulting mixture was stirred and allowed to sediment through a distance of $90 \mathrm{~mm}$, from the initial height, under gravity. The time for every $10 \mathrm{~mm}$ change in height was then recorded.The sedimentation rate was then determined from the plot of the change in height $(\mathrm{CH})$ versus calculated mean time (t). All experiments were done in the morning hours throughout the experimental period and the ambient morning hour temperatures ranged between $27.5^{\circ} \mathrm{C}-29.0^{\circ} \mathrm{C}$.

\section{Results And Discussion}

The sedimentation rate, $R s$, is expressed mathematically(Essien, 1992) as $\mathrm{R}_{\mathrm{s}}=\frac{\mathrm{dx}}{\mathrm{dt}}=\operatorname{Ks}\left[\mathrm{A}^{+\mathrm{n}}\right]^{\mathrm{a}}\left[\mathrm{B}^{-\mathrm{m}}\right]^{\mathrm{b}}$.

The empirical sedimentation orders, (a) and (b), and constant, Ks, were evaluated using equation (1), as

$\log \mathrm{Rs}=\log \mathrm{Ks}+\mathrm{a} \log \left[\mathrm{M}^{2+}\right]+\mathrm{b} \log \left[\mathrm{CO}_{3}{ }^{2-}\right]$

When $\left[\mathrm{M}^{2+}\right]$ is isolated (or kept constant),

$\log \mathrm{Rs}=\log \mathrm{ks}_{1}+\mathrm{b} \log \left[\mathrm{CO}_{3}{ }^{2-}\right]$.

Again, when $\left[\mathrm{CO}_{3}{ }^{2-}\right]$ is isolated (or kept constant)

$\log R s=\log k_{2}+a \log \left[\mathrm{M}^{2+}\right]$.

$\mathrm{ks}_{1}$ and $\mathrm{ks}_{2}$ are the sedimentation rate constants with respect to the cations and anions respectively.

The sedimentation profile plots in Figures 1 and 2 showed the effect of concentration on settling and also a comparison ofthe sedimentation characteristics between magnesium and calcium carbonates. These profilesindicate that the sedimentation rates of $\mathrm{MgCO}_{3}$ and $\mathrm{CaCO}_{3}$ precipitates decrease with increase in concentration of both the metal ions and that of the precipitating agent.The decrease might be due to the colloidal nature of precipitates which increased the tendency of the particles to participate in the electrical double layer effect. Colloidal particles have large-surface-to-mass ratio, which promote surface adsorption (Gary, 2004). Brownian motion (Skoog,et. al., 1995) and an equilibrium-based adsorption process, characteristic of colloidal particles may have determined the initial rate of sedimentation of the precipitates.Excess precipitate particles in solution tend to adsorb on the surfaces of other particles. Smaller particles dissolve and re-precipitate on the surface of larger ones. This results in particle growth and over time these non-settleable colloidal precipitates begin to settle as the constituent particles appreciate in size.Figures 1 and 2 further revealed that magnesium and calcium carbonates had similar sedimentation characteristics, in the precipitation process. This 
might be due to their apparent similarity in density. A correlation (Table 2) of the experimental sedimentation rate constants for $\mathrm{MgCO}_{3}$ and $\mathrm{CaCO}_{3}$ precipitates at variable metal ions concentrations with densities of the puremetals and of the compounds gave a perfect linear relationship $\left(r^{2}=0.9963\right)$.This is in agreement with the assertion by Skoog, et. al., (1995), that, no change in physical properties occur even as particle size increases or decreases with increase or decrease in reactant concentrations. This also suggests that the empirical sedimentation rate constant is an intrinsic property of the sediment- particle which depends among others on the nature of the particle.

Table 1: Sedimentation Rate parameters of magnesium and calcium carbonate precipitates

\begin{tabular}{|c|c|c|c|c|c|}
\hline precipitate & $\begin{array}{l}\text { Sedimentation order } \\
\text { (a) at constant }\left[\mathrm{CO}_{3}{ }^{2-}\right]\end{array}$ & 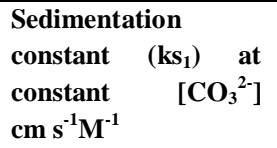 & $\begin{array}{l}\text { Sedimentation order } \\
\text { (b) at constant }\left[\mathrm{M}^{2+}\right]\end{array}$ & 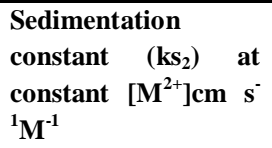 & \begin{tabular}{lr}
\multicolumn{2}{l}{ Calculated } \\
(overall) rate \\
constant \\
$\mathrm{cm} \mathrm{s}^{-1} \mathbf{M}^{-2}$
\end{tabular} \\
\hline $\mathrm{MgCO}_{3}$ & -0.87 & $9.92 \times 10^{-4}$ & -0.79 & $9.87 \times 10^{-4}$ & $9.45 \times 10^{-5}$ \\
\hline $\mathrm{CaCO}_{3}$ & -1.1 & $6.82 \times 10^{-4}$ & -1.8 & $6.92 \times 10^{-5}$ & $4.75 \times 10^{-6}$ \\
\hline
\end{tabular}

Table 2: Correlation of Sedimentation Rate Constants of $\mathrm{MgCO}_{3}$ and $\mathrm{CaCO}_{3}$ Precipitates at variable $\left[\mathrm{M}^{-2}\right]$ with Densities of Metals and of the Compounds

\begin{tabular}{lllllll}
\hline Precipitates & $\begin{array}{l}\text { Density } \\
{\left[\mathrm{gcm}^{-3}\right]}\end{array}$ & of metal (M) & $\begin{array}{l}\text { Density } \\
{\left[\mathrm{gcm}^{-3}\right]}\end{array}$ & of compound & $\begin{array}{l}\text { Sedimentation } \\
\text { constant at variable }\left[\mathrm{M}^{2+}\right] \\
\mathrm{cms}^{-1} \mathrm{M}^{-1}\end{array}$ & $\begin{array}{r}\mathrm{r}^{2} \\
\end{array}$ \\
\hline $\mathbf{M g C O}_{3}$ & $1.70^{*}$ & & $2.958^{*}$ & $9.92 \mathrm{E}-4$ & \\
$\mathbf{C a C O}_{3}$ & 1.60 & 2.71 & $6.82 \mathrm{E}-4$ & 0.9963 \\
\hline
\end{tabular}

* Densities of metals and compounds are adopted from Lee (1987) and SLAC (2014).

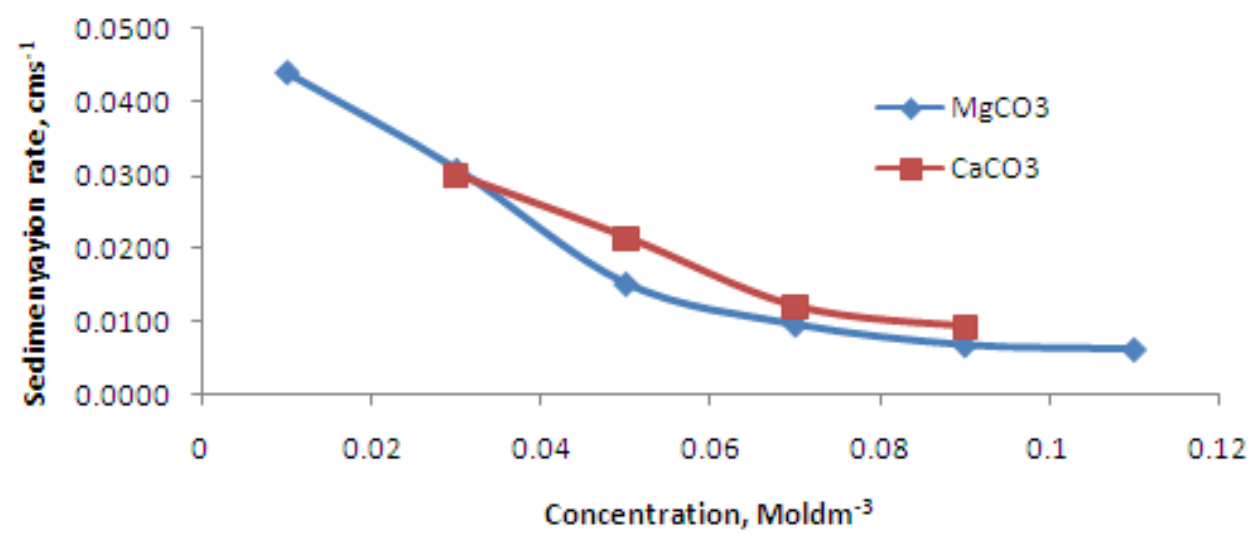

Figure 1: Sedimentation rate profiles of $\mathrm{MgCO}_{3}$ and $\mathrm{CaCO}_{3}$, precipitates at constant $\left[\mathrm{CO}_{3}{ }^{2-}\right]$.

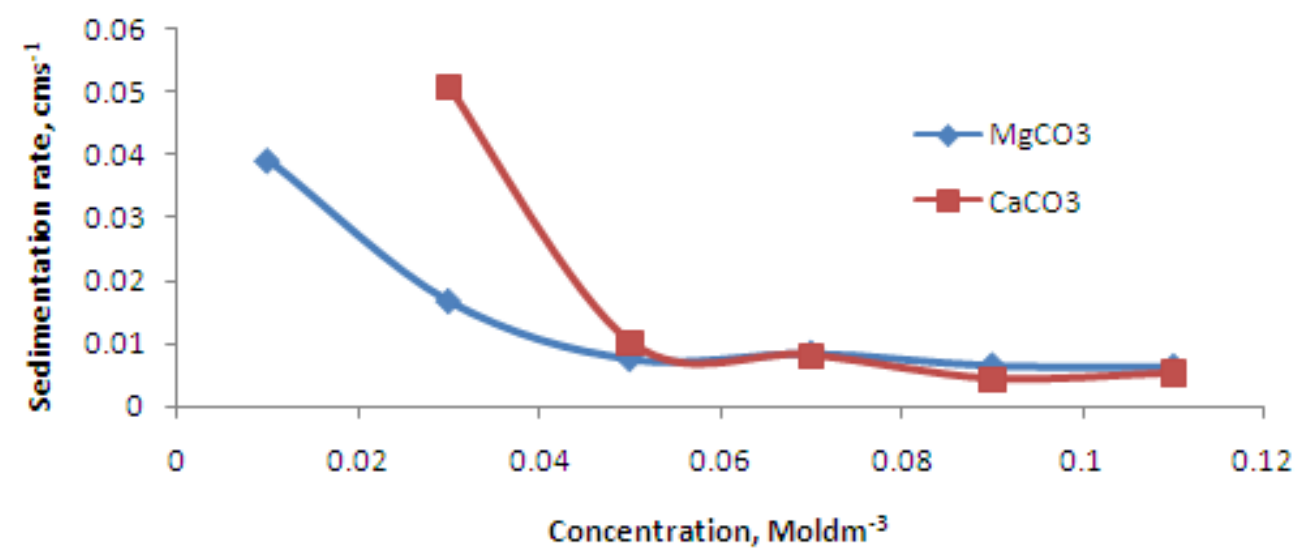

Figure 2: Sedimentation rate profiles of $\mathrm{MgCO}_{3}$ and $\mathrm{CaCO}_{3}$ precipitates at constant $\left[\mathrm{M}^{2+}\right]$. 
Sedimentation of precipitates in cylinders of various sizes.The settling process of precipitates (e.g. $\mathrm{MgCO}_{3}$ )monitored under similar experimental conditions in various cylinderswith different sizes showed a positive increase in rate as the size of the cylinder was increased. The results (Figure 3)indicated an increase in settling rate as the internal diameter of the settling vessel (measuring cylinder) was increased. Lowell and Rose (1991) reported sediment-particles settling velocity in various diameters of a modified bottom withdrawal tube [MBWT]. There was an increase in settling rate as the diameter of the tube was increased.It is apparent that interactions between the particles, slight variations in stirring rate and the low gravitational force on the particles may have affected the correlation as is obtained in Figure 3.

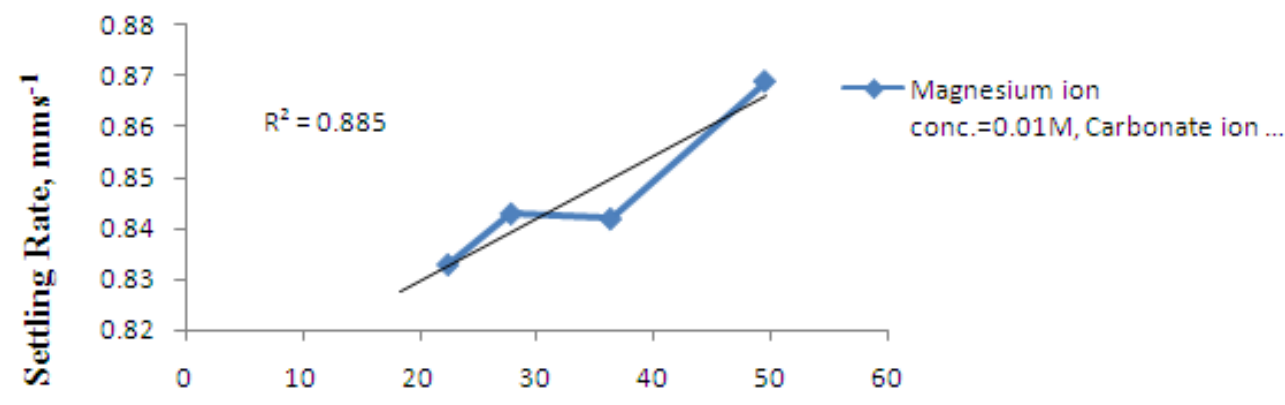

Tube size of measuring cylinder, $\mathrm{mm}$

Figure 3: Correlation of gravitational sedimentation rate as a function of internal diameter of measuring cylinder for $\mathrm{MgCO}_{3}$ precipitates.

Sedimentation at Constant $\left[\mathrm{CO}_{3}{ }^{2-}\right]$ : At constant concentration of the carbonate ion, the sedimentation rates of metal carbonate precipitates decreased with increase in concentration of metal ions (Figure 1).

From the sedimentation order plots(Figure 4), asedimentation order of -0.87 was recorded for $\mathrm{MgCO}_{3}$ precipitates with respect to magnesium ions concentration andan order of -1.1 for $\mathrm{CaCO}_{3}$ precipitates with respect to calcium ions. It was observed thatthere was a rapid disappearance of $\mathrm{CaCO}_{3}$ precipitates at a calcium ion concentration of $0.11 \mathrm{M}$.

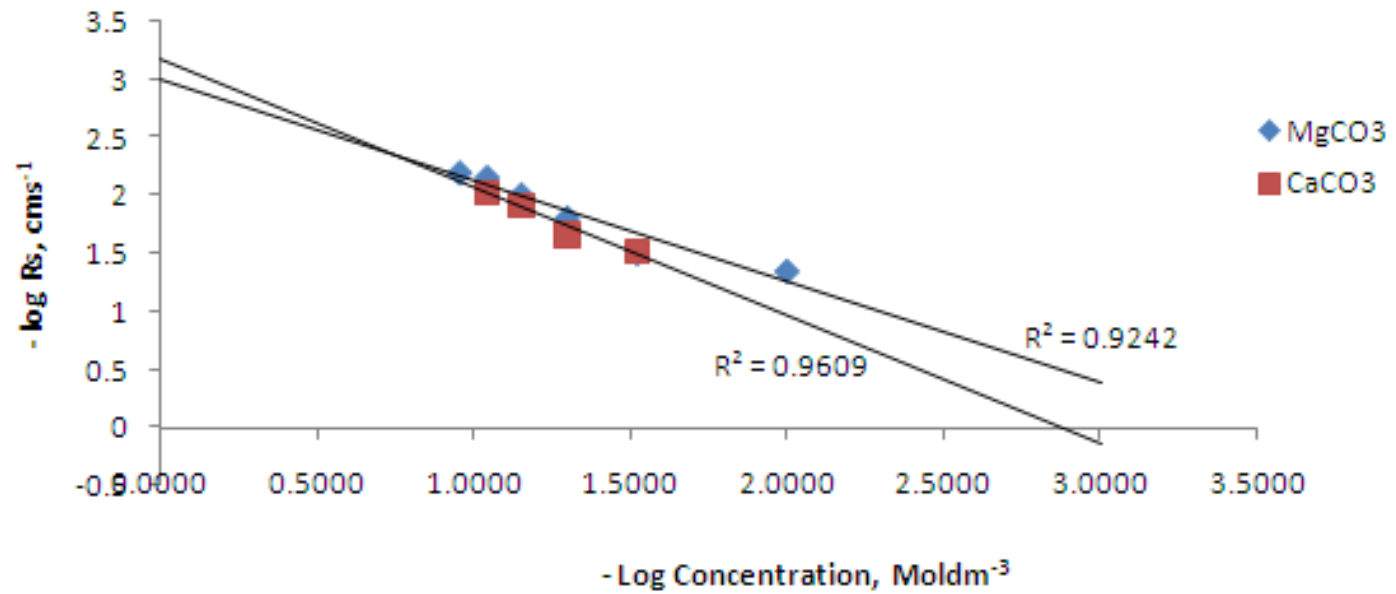

Figure 4: Sedimentation order plots of $\mathrm{MgCO}_{3}$ and $\mathrm{CaCO}_{3}$ at constant $\left[\mathrm{CO}_{3}{ }^{2-}\right]$.

Sedimentation at Constant $\left[\mathrm{M}^{2+}\right]$ : At constant metal ion concentration,the sedimentation rates of the metal carbonate precipitates decreased with increase in concentration of the carbonate ions (Figure 2). Thesedimentation orders of -0.79 and -1.8 for $\mathrm{MgCO}_{3}$ and $\mathrm{CaCO}_{3}$ precipitates were recorded with respect to carbonate ions (Figure 5). 


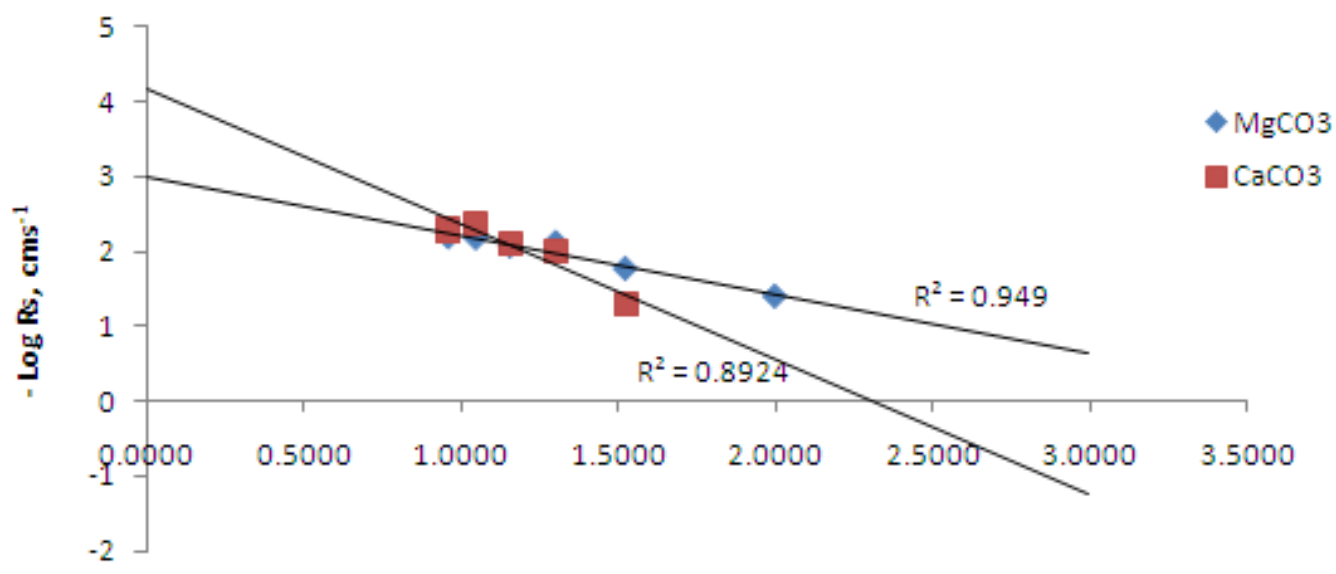

- Log Concentration, Moldm-3

Figure 5: Sedimentation order plots of $\mathrm{MgCO}_{3}$ and $\mathrm{CaCO}_{3}$ precipitates at constant $\left[\mathrm{M}^{2+}\right]$.

\section{Conclusion}

In conclusion, the rates of sedimentation of magnesium and calcium carbonates have been determined by a methodinvolving the free settling of the carbonates undergravity and by the use of a modified approach of the method of isolation. The nature of the precipitates formed and the ionic strength of the medium in which precipitation occurred contributed immensely to the sedimentation process. We systematically varied the interactions and chemical environment of the resulting precipitates by successively varying the concentrations of ions in excess in the mixtures. These variations affected the particle size and the electrical double layers around each particle. The study showed that the sedimentation characteristics of magnesium and calcium carbonates, in precipitation, are affected by reactants ionic concentrations as indicated by correlation coefficient of more than $89 \%$ in all variations.

Gravitational sedimentation study of precipitates in measuring cylinders of various sizes showed a positive increase in settling rate when the sizes of settling vessels were increased. Wall effect (Christie, 2003), pressure gradient, particle shape/crystal structure, and ion-ion/ion-solvent interactions may have contributed to the difference in settling rate in different sized settling vessels.

[1]. Armfield. (2011). W2 sedimentation studies apparatus. Retrieved Novermber 4, $2011 \quad$ from http://www.armfied.co.uk/discoveramfield.com

[2]. Atkins, P. Julio, D. (2006). Atkins physical chemistry (8th ed.). New Delhi, India: Oxford University press.

[3]. Bengt, C. (1998). An introduction to sedimentation theory in wastewater treatment. Uppsala, Sweeden: Uppsala university press.

[4]. Benouali, D., Kacha, S., Kherici, S., \&n Benabadji, N. (2010). study of the flocculated particles sedimentation assisted by microcomputer. The Open Hydrology Journnal, 4 (1), 14-18.

[5]. Christie, G. J. (2003). Transport Processes and Separation Process Principles(4th ed.). London, UK: Prentice Hall.

[6]. Essien, I. O. (1992). Studies on sedimentation of transition metal hyudroxides. Tropical journal of Applied Science, 2, 122125.

[7]. Essien, I. O. (1998). Studies on sedimentation rates and absorption coefficients of some trasition metal sulphides using gamma radiation. Jouirnal of Chemical Society Pakistan, 21, 1303- 1304.

[8]. Essien, I O \&Ekpe, S D (1998). Determination ofsedimentation rates of cobalt(II) insoluble and absorption coefficient of the insoluble metal carbonates. J ApplSci Environ Mgt 10, 123-126.

[9]. Gary, D. (2004). Analytical Chemistry (6th ed.). Singapore: John Wiley.

[10]. Lee, J. D. (1987). A new concise inorganic chemistry (3 rd ed.). Wokingham, Birkshire, UK: Nostrand Reinhold (UK) Co. Ltd.

[11]. Lowell, C. J. \& Rose, C. W. (1991). The effects of sediment concentration and tube-diameter on particle settling velocity measured beyond stokes"range:experiment and theory. Journal of Sedimentary Research, 61 (4), 583-589.

[12]. Mike, R. B., Donald, H., Heidi, L., Susan, M., Gautam, N. \& Irene, W. Y. (1996). Innovative wastewater treatment in the developing world (Unpublished report, Massachusetts Institute of Technology, Cambridge, MA). Retrieved May 12th , 2012, from http://web.mt.edu/watsan/Docs/student\%252

[13]. Mkpenie, V. N. \& Onwu, F. K. (2006). Determination of sedimentation rates and absorption coefficients of insoluble metal carbonates. Journal of Applied Science and Environmental Management, 10 (3), 123-126.

[14]. Murcott, S., Donald, R. F. H. \& Frederic, C. (2001). Approriate wastewater trement in developing countries:experience with CEPT. London: Cambridge.

[15]. Nasser, M. S. \& James, A. E. (2009). The effect of electrolyte concentration and PH on tflocculation andn rheological behaviour of kaolinite suspensions. Journal of Engineering Science and Technology, 4 (4), 430-446.

[16]. Nilufer, K. (2006). A study of channelling behaviour in batch sedimentation. Melbourne, Victoria, Austrlia: (unpublished PhD disertaion) RMIT Univesity. 
[17]. Nongkran, C. \& Apinon, N. (2008). Influence of pH, electronlyte and polymer on floccultation of kaolin particles. Chiang Mai Journal of Science, 35 (11), 11-16.

[18]. Raymond, C. (1981). Physical chemsitry with application to biological systems (2nd ed.). New York: Macmillan.

[19]. Rovshan, M. I. Nikolai, A. S. \& Higmat, K. (2005). Mathematical model describing erythrocytes sedimentation rate: implication for blood viscosityn changes in traumatic shock and crush syndrome. Retrieved May 11th , 2012, from http://www.boimedicalengineering-online.com/content/4/1/24

[20]. Senthilkumar, K. Sivakumar, V. \& Kannadasan, T. (2008). Experimental investigation on relationship between sedimentation rate constants of soild materials. Modern Applied Science, 2 (5), 80 - 85

[21]. Skoog, G. A., West, D. M. \& Holler, F. J. (1995). Fundamentals of Analytical Chemistry (7thed.). Philadelphia, PA: Saunders College. [22]. SLAC. (2014). Physical constants of
http://www.slac.standford.edu/BFROOT/www/Detect/Background/

[23]. Victor, N. M., Goddy, E. \& Beauty, A. (2007). Studies on the effect of temperature on the sedimentation metal carbonates. Journal of Applied Science and Environmental management, 11 (4), 67-69.

compounds. $\quad$ Retrieved from

of insoluble 